\title{
Antimicrobial and larvicidal activities of 2-hydroxypyrrolidine/piperidine derivatives
}

\author{
M. Suresh ${ }^{1 *}$, M. Syed Ali Padusha², A. Raja ${ }^{3}$ \\ ${ }^{1}$ PG Department of Chemistry, L. N. Government College, Ponneri, Tamilnadu, India \\ ${ }^{2} P G$ and Research Department of Chemistry, Jamal Mohamed College, Trichy, Tamilnadu, India \\ ${ }^{3} P G \&$ Research Department of Microbiology, Jamal Mohamed College, Trichy, Tamilnadu, India
}

Received: March 11, 2016; Accepted: March 21, 2016; Published: April 21, 2016

*Corresponding author: M. Suresh, PG Department of Chemistry, L. N. Government College, Ponneri, Tamilnadu, India, Tel no: +91-9865042624; Email : mscsuresh2@gmail.com

\begin{abstract}
A novel series of various 2-hydroxypyrrolidine/piperidine derivatives were synthesized and their antibacterial activity against MTCC bacterial strains, anticancer activity and larvicidal effects were studied. Among the ten synthesized compounds, three were found to be antibacterial in nature. All the five test strains were highly sensitive to 1-(quinolin-3-yl) pyrrolidin-2-ol (P7), moderately sensitive to 1-(pyridin-4-yl) pyrrolidin-2-ol (P3) and less significantly to 1-(pyyrolidin-2-yl) piperidin-2-ol (p8). The maximum zone of inhibition was $28 \pm 0.14 \mathrm{~mm}$ against Escherichia coli (MTCC 78) followed by $23 \pm 0.14 \mathrm{~mm}$ against Klebsiella pneumoniae with 100 percent of relative inhibitory zone. The relative inhibitory zone of P3 against E.coli was $56 \%$ and $80 \%$ against Klebsiella pneumoniae. Similarly 1-(quinolin-3-yl) pyrrolidin-2-ol (P7) showed a $60 \%$ of larvicidal activity against Anaphelous sp and 53\% against Culex sp.
\end{abstract}

Keywords: Pyrrolidine; Piperidine; E.coli; Relative inhibitory zone; Culex

\section{Introduction}

Heterocyclic compounds especially pyrrolidine and piperidines are considered as pharmaceutically important biologically active compounds have been used as Vitamins, hormones and antibiotics [1-3]. Pyrrolidine and piperidine occupied a unique place in the development of pharmacologically active substance by replacing the nucleus [4, 5]. Piperidine nucleus is an important core of many drug molecules. Piperidine and its analogues are reported in literature for varied pharmacological activities like antihistamines, anticancer, and antibacterial [6]. The tetrahydropyrrolidine moiety is present in various natural products and they exhibit a broad range of biological activities. Codonopsinine and Codonopsine are the derivatives of pyrrolidine, isolated from Codonopsis chematidea, which have been found to possess hypotensive pharmacological activity [7]. Lilidine, an alkaloid occurring in the epigeal parts of Lilium Martagon which contains pyrrolidine analog has been isolated and reported [8]. $\mathrm{N}$-alkylated-D-fagomine derivatives and $\mathrm{N}$-alkylated hydroxylated pyrrolidine bearing an improved inhibitory selectivity towards $\alpha$-D-glucosidase and
$\alpha$-L-fucosidase, respectively. Cell lines compared to their nonalkylated progenitors. Barbara et al., have been reported a series of 1-substituted pyrrolidin-2-one and pyrrolidine derivatives were synthesized and tested for electrocardiographic, antiarrhythmic and antihypertensive activity as well as adrenoceptors binding affinities [8-10]. Biologically active alkaloids of substituted piperidines ring system have been targeted for their total or partial synthesis. Piperidine was first isolated from the alkaloid piperine, which occurs in black pepper. Piperidine fragment was substituted via variety of synthetic reactions to develop more improved moieties with enhanced activities and to suppress the side effects when taken as medicine for different ailments. Specifically, piperidine based chemical entities with aryl substituent's have been documented as potent microbial agents [9]. Developing antimicrobial drugs and maintaining their potency, in opposition to resistance by different group of microorganisms as well as a broad spectrum of antimicrobial activity major concern of research in this area. Mosquito's are one of the major vectors responsible for the transmittance of diseases to more than 700 million people annually. Control of such diseases is becoming increasingly difficult because of increasing resistance of mosquitoes to pesticides [11].

\section{Experimental Studies}

All anhydrous solvents and reagents were obtained from commercial suppliers and used without any further purification unless otherwise noted [Merck and Alfa Aesar products]. All the reactions were carried out in the closed condition. The melting points of the synthesized compounds were measured on EZ - Melt automated melting point apparatus. IR spectra were recorded on Shimadzu FT-IR spectrometer using $\mathrm{KBr}$ pellet in the 400 $4000 \mathrm{~cm}^{-1}$ region. The IR spectra were recorded from St. Joseph College, Trichy. The NMR spectral studies were carried out using Bruker $300 \mathrm{MHz}$ spectrometer using TMS as an internal standard and DMSO- $\mathrm{d}_{6}$ as solvent and recorded at Sastra University, Tanjore. Mass spectra were recorded on a JEOL GCMATE II GC-MS spectrometer using a direct injection method. The mass spectra were recorded from IIT Madras, Chennai. 


\section{General Synthesis of 2-hydroxypyrrolidine/piperidine derivatives}

Among the different approaches employed for the synthesis of 2-hydroxypyrrolidine and piperidine derivatives, one pot synthesis method is the most efficient. To the mixture of 2,3-cyclic ethers and acetonitrile, heterocyclic amine was added and followed by $\mathrm{CeCl}_{3} \cdot 7 \mathrm{H}_{2} \mathrm{O}$. The reaction condition was maintained at $60{ }^{\circ} \mathrm{C}$ using silicone oil bath and the contents were kept over a magnetic stirrer and stirred well. The colorless was solid separated and washed several times with water [1214].

\section{Antimicrobial effect of 2- hydroxy Pyrrolidine/ Piperdine derivatives $(\mathbf{1 1}=15)$}

The antibiotic sensitivity of the isolates was determined using the disc diffusion method. Standardized inoculum of the 0.5 Mcfarnald overnight grown Nutrient agar culture of $E$. coli (MTCC 78), P. aeruginosa (MTCC 2488), S. aureus (MTCC 96), B. subtilis (MTCC 121), K. pneumoniae (MTCC 109) were spread on Mueller-Hinton agar plates using sterile swabs. The plates were dried at room temperature for $20 \mathrm{~min}$ and $100 \mu \mathrm{l}(5 \mathrm{mg} / \mathrm{ml})$ of synthesized pyrrolidine and piperidine derivatives loaded on their respective wells and allowed to diffuse. The plates were incubated for $24 \mathrm{~h}$ at $37^{\circ} \mathrm{C}$. All the tests were triplicate and the diameter of zone of inhibition was measured and statistically reported [15].

\section{Screening of larvidial effect of 2- hydroxy Pyrrolidine/ Piperdine derivatives}

About $100 \mathrm{ml}$ of sterile tap water was taken in conical flask and one $\mathrm{ml}$ of pyrrolidine and piperidine derivatives were added to obtain $10 \mathrm{ppm}$ concentration. The control tubes were maintained as tap water alone. 25 numbers of $3^{\text {rd }}$ instar Anopheleses and Culex mosquito larvae were inoculated into the above tubes and incubated at $2^{\circ} \mathrm{C}$ for $48 \mathrm{~h}$. The larvicidal activity was observed for over $30 \mathrm{~min}$. and death of the larvae confirmed the larvicidal activity. The experiment was checked daily for recording the biological effects of following criterias [19].

Larval mortality percent: was estimated by using the following equation:

Larval mortality $\%=\mathrm{A}-\mathrm{B} / \mathrm{A} \times 100$

Where $\mathrm{A}=$ number of tested larvae and $\mathrm{B}=$ number of tested pupa

Papal mortality $\%=\mathrm{A}-\mathrm{B} / \mathrm{A} \times 100$

Where $\mathrm{A}=$ number of produced pupae and $\mathrm{B}=$ number of observed adults.

Adult emergence $\%=\mathrm{A} / \mathrm{B} \times 100$

Where $\mathrm{A}=$ number of emerged adults and $\mathrm{B}=$ number of tested pupae.

\section{Results and discussion}

\section{Synthesis and characterization}

Synthesis of 1-(quinolin-3-yl)pyrrolidin-2-ol (P7): To a solution of 3-aminoquinoline $(1.18 \mathrm{mmol})$ in acetonitrile $(5 \mathrm{~mL})$, 2,3-dihydrofuran (1.4 mmol) was added followed by cerium chloride hexa hydrate $\left(\mathrm{CeCl}_{3} \cdot 6 \mathrm{H}_{2} \mathrm{O}\right)(0.59 \mathrm{mmol})$ at $0^{\circ} \mathrm{C}$. The reaction mixture was kept in an oil bath maintained at $60^{\circ} \mathrm{C}$ and stirred well for $30 \mathrm{~min}$. Progress of the reaction was continuously monitored by LCMS. The reaction mixture was diluted with ethyl acetate and washed with water. The organic layer was dried over $\mathrm{Na}_{2} \mathrm{SO}_{4}$ and concentrated by vacuum. The crude mass obtained was purified by column Chromatography packed with $60 / 120$ silica gel and eluted with $25-35 \%$ ethyl acetate in petroleum ether. The above procedure was employed for the preparation of remaining compounds.

Characterization: Series of new 2 hydroxy pyrrolidine (fig 1) and piperidine (fig 2) derivatives were synthesized and the structure of compound was elucidated by elemental analysis, ${ }^{1} \mathrm{H}$ NMR (Fig 3 \& 4), ${ }^{13} \mathrm{C}$ NMR and mass spectra. 1-(quinolin-3-yl)pyrrolidin-2-ol (P7) was synthesized from 2,3-dihydrofuran and quinolin-3-amine. Yield: 85\%. M.P. 198$200^{\circ} \mathrm{C},{ }^{1} \mathrm{H}$ NMR $\delta$ in ppm $\left(300 \mathrm{MHz}, \mathrm{DMSO}-\mathrm{d}_{6}\right): 8.51(\mathrm{~s}, 1 \mathrm{H}, \mathrm{OH})$, 7.84-7.50(m, 6H, naphthalene ring), 5.10(s, $1 \mathrm{H}), 3.41(\mathrm{~m}, 2 \mathrm{H})$, 2.74-2.55(m, 2H), 2.25-1.78(m, 2H) (pyrrolidine). ${ }^{13} \mathrm{C}$ NMR $\delta$ in ppm (100 MHz, DMSO-d $)$ 151, 148, 144, 136, 132, 129, 128, 127, 126(naphthalene), 92, 54, 38, 24(pyrrolidine) $\mathrm{M} / \mathrm{z}=214(\mathrm{M}+1)$. Elemental Analysis: $\mathrm{C}_{13} \mathrm{H}_{14} \mathrm{~N}_{2} \mathrm{O}$. Found (\%): $\mathrm{C}=72.76, \mathrm{H}=6.55$, $\mathrm{N}=13.12, \mathrm{O}=7.62$. Calcd: $\mathrm{C}=72.87, \mathrm{H}=6.59, \mathrm{~N}=13.07, \mathrm{O}=7.47$.

1-(pyrazin-2-yl) piperidin-2-ol (PP8) was synthesized from 3, 4-dihydro-2H-pyran and pyrazin-2-amine. Yield: 94\%. M.P. 244$246^{\circ} \mathrm{C},{ }^{1} \mathrm{H}$ NMR $\delta$ in ppm $(300 \mathrm{MHz}$, DMSO-d $)$ : $9.14(\mathrm{~s}, 1 \mathrm{H}, \mathrm{OH})$, 8.52-8.31 (m, 2H, pyrazine) $4.61(\mathrm{q}, 1 \mathrm{H}) 3.40-3.23(\mathrm{~m}, 2 \mathrm{H}) 2.30-$ $2.10(\mathrm{~m}, 2 \mathrm{H})$ 1.70-1.60 (m, 2H) 1.52-1.43 (m, 2H) (piperidine). ${ }^{13} \mathrm{C}-\mathrm{NMR} \delta$ in ppm $(100 \mathrm{MHz}$, DMSO-d $) 161,151,141$ (3C, pyrazine), 93, 49, 38, 27, 21 (5C, piperidine). $\mathrm{M} / \mathrm{z}=179(\mathrm{M}+1)$. Elemental Analysis: $\mathrm{C}_{9} \mathrm{H}_{13} \mathrm{~N}_{3} \mathrm{O}$. Found (\%): $\mathrm{C}=60.32, \mathrm{H}=7.88$, $\mathrm{N}=23.65, \mathrm{O}=8.44$. Calcd: $\mathrm{C}=60.32, \mathrm{H}=7.31, \mathrm{~N}=23.45, \mathrm{O}=8.93$.

Antimicrobial activity of 2- hydroxy Pyrrolidine/ Piperdine derivatives: Out of ten compounds 1-(pyridin-4-yl) pyrrolidin-2-ol, 1-(quinolin-3-yl)pyrrolidin-2-ol and 1-(pyrazin2-yl)piperidin-2-ol (P3,P7 P8) were found to be active against

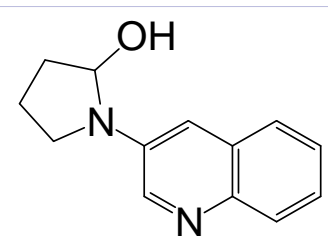

Figure 1: Structure of 1-(quinolin-3-yl) pyrrolidin-2-ol (P7).

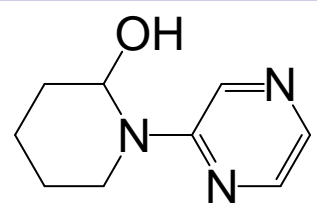

Figure 2: Structure of 1-(pyrazin-2-yl)piperidin-2-ol (PP8). 


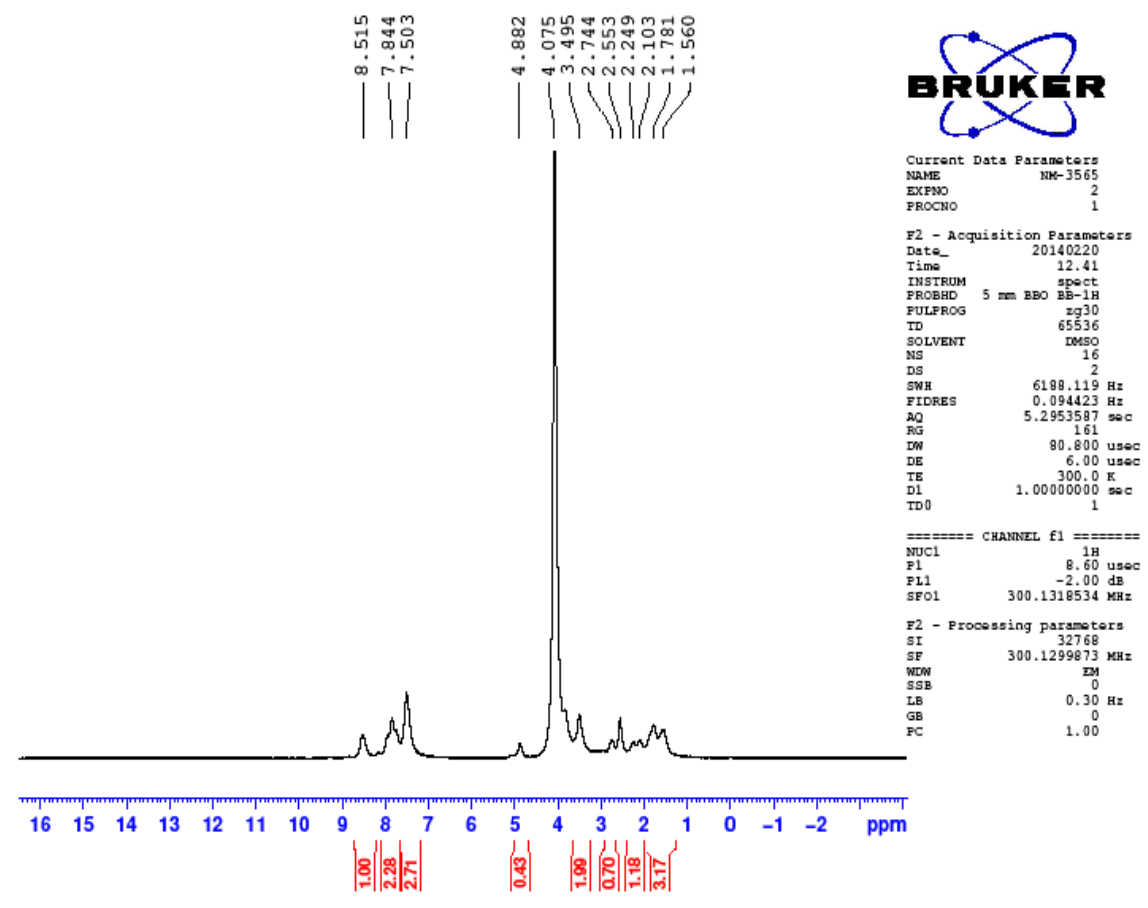

Figure 3: ${ }^{1} \mathrm{H}$ NMR spectrum of 1-(quinolin-3-yl)pyrrolidin-2-ol (P7) ).

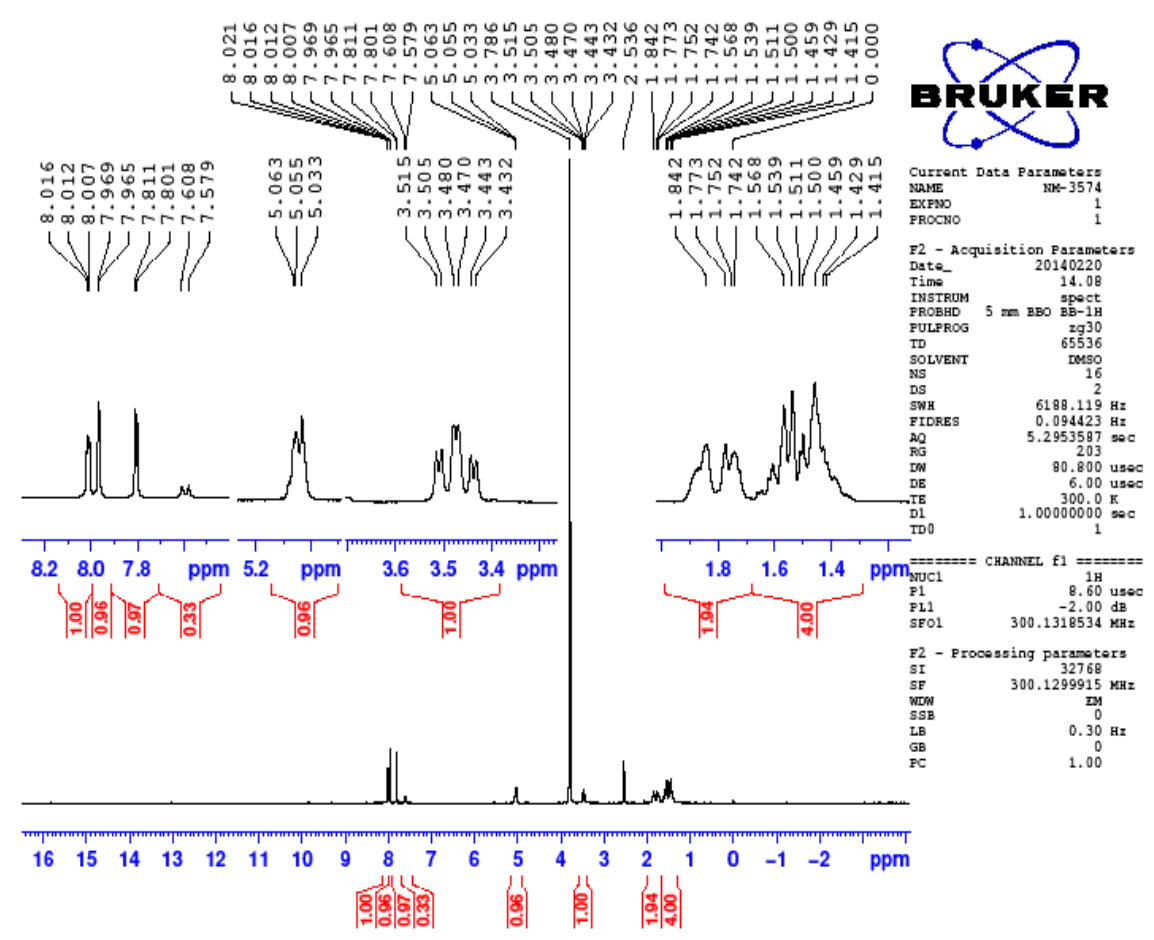

Figure 4: ${ }^{1} \mathrm{H}$ NMR spectrum of 1-(pyrazin-2-yl)piperidin-2-ol (PP8). 


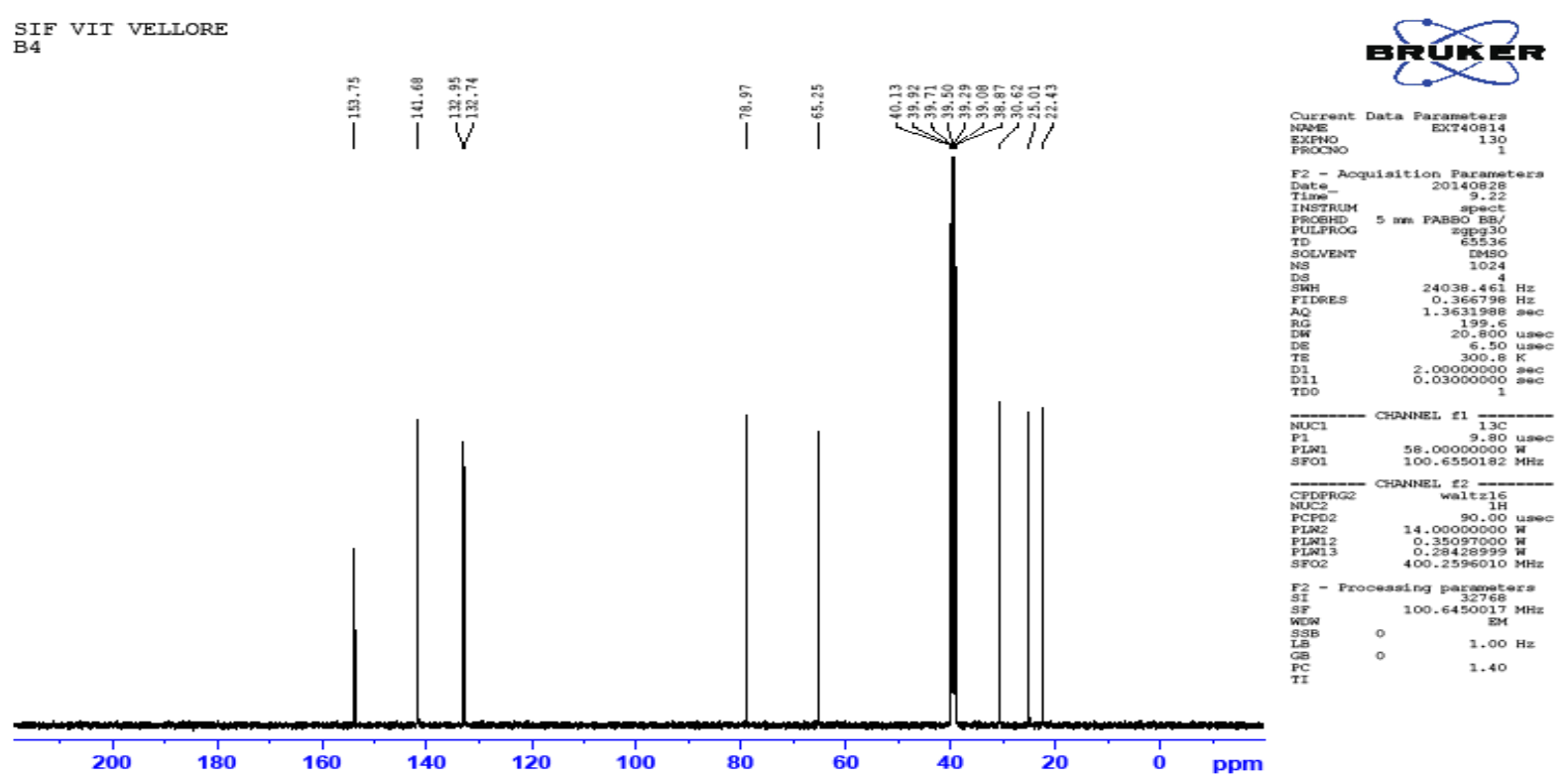

Figure 5: ${ }^{13} \mathrm{C}$ NMR spectrum of 1-(pyrazin-2-yl)piperidin-2-ol (PP8).

all tested bacterial strains and showed broad spectrum antimicrobial activity against Gram negative and less extend to against Gram positive Bacillus sp. The experimental result of antimicrobial activity indicated variable degree of efficacy of the compounds against different microbial strains (Table 1). Among the three active compounds, piperdine derivative P7 1-(quinolin3-yl) pyrrolidin-2-ol showed potent antimicrobial activity against tested bacterial strains. All the five tested pathogens were highly sensitive to P7 1-(quinolin-3-yl) pyrrolidin-2-ol. Of these five sensitive strains, E.coli and K. pneumoniae were Highly sensitive to 1-(quinolin-3-yl) pyrrolidin-2-ol and 1-(pyridin-4-yl) pyrrolidin2-ol (P3). E.coli and K. pneumoniae have shown 100 percent relative inhibitory zone against 1-(quinolin-3-yl) pyrrolidin-2ol(P7). The least Relative Inhibitory zone of 1-(quinolin-3-yl) pyrrolidin-2-ol (P7) was 12.5\% (16 $\pm 0.29 \mathrm{~mm}$ ) against Bacillus subtilis. The results revealed that above synthesized compounds exhibited good antimicrobial activity comparable to rifampicin against all tested pathogens. Antimicrobial activity of compounds containing nature of functional linkage [16] and substituted aromatic ring [17] has been reported. A series of 4-substituted 4-(1H-1,2,3-triazol-1-yl)piperidine building blocks was found to be active against against multidrug-resistant strains, especially to Staphylococcus aureus and Staphylococcus epidermidis [18].

Larvicidal activity of 2- hydroxy Pyrrolidine/ Piperdine derivatives: Among the 2-hydroxypyrrolidine/piperidine series seven were showed larvicidal activity against Culex $s p$ and Anopheles $s p$. The maximum larvicidal activity was $64 \%$ by P7 1-(quinolin-3-yl) pyrrolidin-2-ol against Anopheles sp (table 2) followed by $62 \%$ by P8 1-(pyrazin-2-yl) pyrrolidin-2-ol against culex sp (table 3) with the dosage of 50 ppm. 1-(quinolin-3-yl) pyrrolidin-2-ol showed strong larvicidal and pupicidal activity against both tested larvae. Similarly piperdine derivatives also showed significant larvicidal effect againt Culex (58\%) and

Table 1: Antimicrobial activity of 2- hydroxy Pyrrolidine/ Piperdine derivatives.

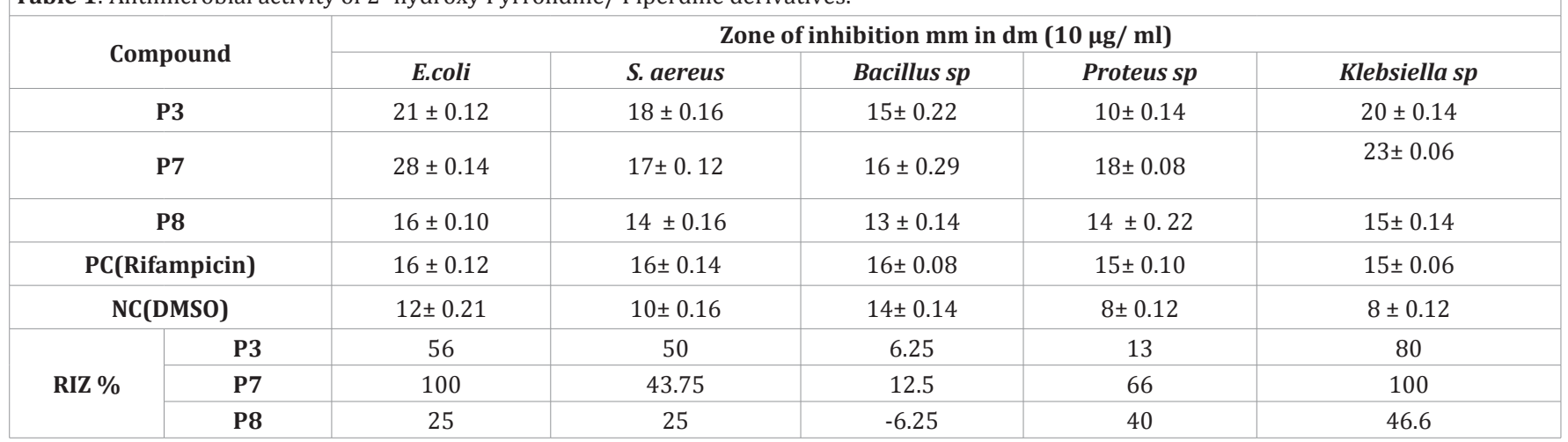


Table 2: Larvicidal activity of 2- hydroxy Pyrrolidine/ Piperdine derivatives against Anopheles sp.

\begin{tabular}{|c|c|c|c|c|}
\hline S. No & Compd. Name & $\begin{array}{c}\text { Larvicidal } \\
\text { Mortality(\%) }\end{array}$ & $\begin{array}{c}\text { Pupal } \\
\text { Mortality (\%) }\end{array}$ & Adult emergence (\%) \\
\hline 1 & Pp8 1-(pyrazin-2-yl)piperidin-2-ol & 48 & 38 & 62 \\
\hline 2 & Pp6 1-(pyrimidin-2-yl)piperidine-2-ol & 36 & 31 & 69 \\
\hline 3 & Pp4 1-(5-methyl-1,3,4-thiadiazol-2-yl)piperidin-2-ol & 40 & 53 & 47 \\
\hline 4 & P8 1-(pyrazin-2-yl)pyrrolidin-2-ol & 40 & 43 & 45 \\
\hline 5 & P7 1-(quinolin-3-yl)pyrrolidin-2-ol & 64 & 55 & 50 \\
\hline 6 & P4 1-(5-methyl-1,3,4-thiadiazol-2-yl)pyrrolidin-2-ol & 60 & 50 & 82 \\
\hline 7 & P3 1-(pyridin-3-yl)pyrrolidin-2-ol & 36 & 18 & 65 \\
\hline 8 & DMSO & 44 & 35 & 74 \\
\hline 9
\end{tabular}

Table 3: Larvicidal activity of 2- hydroxy Pyrrolidine/ Piperdine derivatives against Culex sp.

\begin{tabular}{|c|c|c|c|c|}
\hline S. No & Compd. Name & $\begin{array}{c}\text { Larvicidal } \\
\text { Mortality (\%) }\end{array}$ & $\begin{array}{c}\text { Pupal } \\
\text { Mortality (\%) }\end{array}$ & Adult emergence (\%) \\
\hline 1 & Pp8 1-(pyrazin-2-yl)piperidin-2-ol & 58 & 100 & 0 \\
\hline 2 & Pp6 1-(pyrimidin-2-yl)piperidine-2-ol & 31 & 50 & 50 \\
\hline 3 & Pp41-(5-methyl-1,3,4-thiadiazol-2-yl)piperidin-2-ol & 51 & 100 \\
\hline 4 & P8 1-(pyrazin-2-yl)pyrrolidin-2-ol & 62 & 100 & 0 \\
\hline 5 & P7 1-(quinolin-3-yl)pyrrolidin-2-ol & 53 & 100 & 0 \\
\hline 6 & P4 1-(5-methyl-1,3,4-thiadiazol-2-yl)pyrrolidin-2-ol & 42 & 100 & 0 \\
\hline 7 & P3 1-(pyridin-4-yl)pyrrolidin-2-ol & 40 & 100 & 0 \\
\hline 8 & DMSO & 40 & 90 & 10 \\
\hline 9 & Water & 31 & 50 & 50 \\
\hline
\end{tabular}

Anopheles (48\%). Larvicidal activity of Piperdine from natural sources already reported [19-22].

\section{Conclusion}

Result of present study demonstrates that, a new class of 2-hydroxypyrrolidine \& 2-hydroxypiperidine derivatives were synthesized and evaluated as antibacterial agents. The newly synthesized heterocyclics 1-(quinolin-3-yl) pyrrolidin2-ol (P7)) exhibited promising antibacterial, anticancer activity and larvicidal activity at minimal concentration level. It can be concluded that this class of compounds certainly holds great promise towards medicinal chemistry. A further study to acquire more information concerning pharmacological activity is in progress. To exploit these findings for human welfare, it is necessary to carry out field trials and in vivo studies to explore as valuable bioactive substance.

\section{Acknowledgement}

The authors thank the Principaland Management for providing necessary facilities to carry out this work at the laboratory of PG and Research Department of Chemistry, Jamal Mohamed College Trichy-20. Authors M. Suresh and M. Syed Ali Padusha thank the UGC-New Delhi for financial assistance through Major Research Project (Ref. No. 41-261/2012 (SR) Dated. 13-072012). We thank the STIC Cochin, Sastra University Tanjore, SAIF
IIT Chennai and Dept of Microbiology, Jamal Mohamed College Trichy for analytical support and biological activities.

\section{References}

1. Singh N, Nargund SL, Rashmi P, Nargund LVG. Synthesis and antibacterial and anti-inflammatory activity of 4- substitutedthieno[2,3-d]pyrimidines. Der Chemica Sinica. 2012;3(1):198.

2. Jayadevappa HP, Nagendrappa G, Umesha S, Chandrashekar S. Synthesis and antimicrobial study of N-[4-(2- piperidine-1-yl-ethoxy) phenyl] acetamide analogues. J. App. Pharm. Sci. 2012;2(3):192-196.

3. Nagano R, Adachi Y, Imamura H, Yamada K, Hashizume T, Morishima H. Carbapenem derivatives as potential inhibitors of various betalactamases, including class B metallo-beta-lactamases. Antimicrob. Agents Chemother. 1999;43(10):2497-2503.

4. Stefania M, Maddalena R, Piero V, Paolo DR. Flavone and xanthone derivatives related to fluoroquinolones. Farmaco. 1999;54(6):411415.

5. Kai L, Ming-Liang L, Lian-Shun F, Lan-Ying S, Ye-Xin S, Zeng-Quan W, et al. Synthesis and antibacterial activity of naphthyridone derivatives containing mono/difluoro-methyloxime pyrrolidine scaffolds. Eur. J. Med. Chem. 2012;47(1):619-625. doi: 10.1016/j.ejmech.2011.10.048.

6. Chang Yong H, Young Kwan K, Jay Hyok C, Se Ho K, Hoon C, Do Hyun N, et al. Novel Fluoroquinolone Antibacterial Agents Containing OximeSubstituted (Aminomethyl) pyrrolidines: Synthesis and Antibacterial Activity of 7-(4-(Aminomethyl)-3-(methoxyimino)pyrrolidin-1-yl)1-cyclopropyl-6-fluoro-4-oxo-1,4 dihydro [1,8]naphthyridine-3- 
carboxylic Acid (LB20304). J. Med. Chem. 1997;40(22):3584-3593.

7. Yoda $H$, Nakajima $T$, Takabe. Total synthesis of natural (-)-codonopsinine employing stereoselective reduction of quaternary $\alpha$-hydroxypyrrolidine. Tetrahedren Lett. 1996;37(31):5531-5534. doi:10.1016/0040-4039(96)01042-8.

8. Nagasaka T, Yamamoto $H$, Hayashi H, Watanabe M, Hamaguchi $F$. Witting Reactions of 1-Alkoxycarbonyl-2-hydroxypyrrolidines and -piperidines: Syntheses of $( \pm)$-Hygrine and $( \pm)$-2-Epilasubine II. Heterocycles. 1989;29(1):155-164

9. Abdullaev ND, Samikov K, Antsupova TP, Yagudaev MR, Yunusov SV Structure of iodine. Chem. Nat. Compds. 1987;23:576.

10. Xian-Chao Cheng, Qiang Wanga, Hao Fanga, Wei Tangb, Wen-Fang $\mathrm{Xu}$. Design, synthesis and evaluation of novel sulfonyl pyrrolidine derivatives as matrix metalloproteinase inhibitors. Bioorg. Med. Chem. 2008;16(1):5398-5404. doi:10.1016/j.bmc.2008.04.027

11. Sangshetti JN, Nagawade RR, Shinde DB. Synthesis of novel 3-(1-(1-substituted piperidin-4-yl)-1H-1,2,3-triazol-4-yl)-1,2,4oxadiazol-5(4H)-one as antifungal agents. Bioorg. Med. Chem. Lett. 2009;19(13):3564-3567. doi:10.1016/j.bmcl.2009.04.134.

12. Suresh Mani, Mashood Ahamed Fazul Mohamed, Abdul Khader Karakkakal, Syed Ali Padusha Mohamed Khan. FeCl3-catalysed C-N coupling reaction between cyclic ethers and heterocyclic amines. Eur. J. Chem. 2004;5(4):612-617.

13. Suresh M, Khader KK Abdul, Chandrasekaran T, Padusha M Syed Ali. Synthesis and characterization of N-Substituted 2-hydroxy pyrrolidine/piperidine derivatives using cerium chloride as catalyst. IJC-B. 2015;54B(08):999-1004.

14. Suresh M, Syed Ali Padusha M, Govindarasu K, Kavitha E. Synthesis, structural and spectral analysis of 1-(pyrazin-2-yl) piperidin-2-ol by density functional theory. Spectrochim Acta A Mol Biomol Spectrosc. 2015;138:271-82. doi: 10.1016/j.saa.2014.11.063.

15. Putta P Varma, Kittappa M Mahadevan, Abdul Khader, Vijaykumar
Hulikal. One pot synthesis of 2-hydroxy pyrrolidine derivatives. Org. Commun. 2011;4(3):52-57.

16. Barbara Malawskaa, Katarzyna Kuliga, Barbara Filipekb, Jacek Sapab, Dorota Maciągb, Małgorzata Zygmuntb, et al. Synthesis, antiarrhythmic, and antihypertensive effects of novel 1-substituted pyrrolidin-2-one and pyrrolidine derivatives with adrenolytic activity. Eur. J. med. Chem. 2002;37(3):183-195. doi:10.1016/S02235234(01)01321-6

17. Malik I, Bukovsky M, Andriamainty F, Galisinova J. Antimicrobial activity of meta-alkoxyphenylcarbamates containing substituted N-phenylpiperazine fragment. Braz. J. Microbiol. 2012;43(3):959-965.

18. Alsughayer A, Elassar AA, Mustafa S, Sagheer FA. Synthesis, structure analysis and antibacterial activity of new potent sulfonamide derivatives. J. Biomater. Nanobiotech. 2011;2(2):143-148.

19. Huang X, Zhang A, Chen D, Jia Z, Li X. 4-Substituted 4-(1H-1,2,3triazol-1-yl)piperidine: Novel C7 moieties of fluoroquinolones as antibacterial agents. Bioorg. Med. Chem Lett. 2010;20(9):2859-2863. doi: 10.1016/j.bmcl.2010.03.044

20. Briggs JD. Reduction of adult house-fly Emergence by the Effects of Bacillus sp. on the Development of Immature Forms. Journal of Insect Pathology. 1960;2(4):418-432.

21. Heilam Wong†, Ethel C Garnier-Amblard, Lanny S Liebeskind. Organometallic Enantiomeric Scaffolding: A Strategy for the Enantiocontrolled Construction of Regio- and Stereodivergent Trisubstituted Piperidines from a Common Precursor. J. Am. Chem. Soc. 2011;133(19):7517-7527. DOI: 10.1021/ja201012p.

22. K Balaraman. Mosquito control potential of Bacillus thuringiensis subsp. israelensis and Bacillus sophaericus. ICMR Bull. 1995;25-45.

23. Lee SE. Mosquito larvicidal activity of pipernonaline, a piperidine alkaloid derived from long pepper, Piper longum. J. Am. Mosq. Control. Assoc. 2000;16(3):245-247. 